\title{
Interactive comment on "Gas-phase chemistry in the online multiscale NMMB/BSC Chemical Transport Model: Description and evaluation at global scale" by Alba Badia et al.
}

\section{Alba Badia et al.}

oriol.jorba@bsc.es

Received and published: 11 November 2016

Reply to SC1: 'Executive Editor Comment on "Gas-phase chemistry in the online multiscale NMMB/BSC Chemical Transport Model: Description and evaluation at global scale"', Astrid Kerkweg, 16 Jun 2016

Dear Executive editor of GMD,

Following the Editorial guidelines we have included the model version in the title. 
spheRe CHemistry model". In the responses to the reviewer's comments we keep the NMMB/BSC-CTM name to keep consistency with the manuscript submitted to GMDD, but in the revised manuscript the new name, NMMB-MONARCH, is used.

Now, the revised manuscript is entitled "Description and evaluation of the Multiscale Online Nonhydrostatic AtmospheRe CHemistry model (NMMB-MONARCH) version 1.0: gas-phase chemistry at global scale".

Interactive comment on Geosci. Model Dev. Discuss., doi:10.5194/gmd-2016-141, 2016. 